Vol. 4, No. 2, 2018

Roman Kachmar ${ }^{1}$, Andrii Muzychuk ${ }^{2}$, Olena Lanets ${ }^{3}$, Yurii Porokhovskyi ${ }^{4}$

1. Department of Operation and Repair of Automotive Vehicles, Lviv Polytechnic National University, Ukraine, Lviv, S. Bandery street 12, E-mail: katchmar@i.ua

2. Department of Operation and Repair of Automotive Vehicles, Lviv Polytechnic National University, Ukraine, Lviv, S. Bandery street 12, E-mail: katchmar@i.ua 3. Department of Technical Mechanics and Dynamics of Machines, Lviv Polytechnic National University, Ukraine, Lviv, S. Bandery street, 12, E-mail: lanecolena@gmail.com 4. Department of Operation and Repair of Automotive Vehicles, Lviv Polytechnic National University, Ukraine, Lviv, S. Bandery street 12, E-mail: E-mail: Yurii.V.Porokhovskyi@lpnu.ua

\title{
THE INFLUENCE OF THE VEHICLE'S SUSPENSION MALFUNCTION ON ITS OPERATIONAL EFFICIENCY
}

Received: November 10, 2018 / Revised: December 24, 2018 / Accepted: December 26, 2018

(C) Kachmar R., Muzychu A., Lanets O., Porokhovskyi Yu., 2018

Abstract. The main malfunctions that arise when operating a vehicle in Ukraine are the failure of the suspension elements and vehicle tires due to the poor condition of the most roads [11]. The car suspension elements soften the dynamic loads and smooth out the oscillations from the unevenness on the road while riding and provide a good stability and smoothness of the car ride. The car suspension affects not only the handling, stability, stability of the car motion, but also provides comfort and safety of the car, especially, when car is driven on uneven surface of the road and in sharp manoeuvres of the movement. The suspension of the car is a connecting linkage between the wheels and the body of the vehicle through which the forces of the shocks from wheel act on the vehicle body while riding over bumps on the road. Also, especially the front suspension of the car smooths the oscillations from the uneven road and provides the smooth ride. The smoothness of the ride depends on the elasticity of the suspension and car tires, work of shock absorbers and distribution of the vehicle mass. Besides, the smoothness of the ride on the uneven road has the influence on the comfort of the driver and passengers, the average speed of movement (as a consequence it causes the changes in fuel consumption, productivity and cost of transportation), the cargos safety, the reliability of the car.

The car suspension is one of the least reliable and durable elements of the car. The work of the faulty suspension reduces the durability of the car in 1.5 times and worsens its steering, thereby reducing its safety [11]. Ultimately, the motion of a car with a faulty suspension can cause an emergency on the road due to possible unpredictable suspension behavior.

The analyzing of the typical malfunctions of the car suspension components and its influence on smoothness and safety of motion is provided in the article. The methods of experimental research of the influence of the typical suspension malfunctions on the parameters of the car motion have been developed. The choice of research tools and the mounting place of the sensors on a car suspension is substantiated. On the basis of the experimental research results, the analysis of the influence of the suspension malfunction on the car's condition was performed according to the voltage changing of the sensor-analyzer, and the voltage change was transformed into the linear displacement of the suspension elements.

With the use of the MATLAB program in Simulink mode the simulation of the car ride over the typical obstacles with the use of a two-mass structure for sprung and unsprung masses was carried out, the oscillations of the unsprung and sprung masses were obtained in relation to the road with given pressure in the tire and given speed when riding over various types of obstacles with the normal and faulty shock absorbers. 


\section{The Influence of the Vehicle's Suspension Malfunction on its Operational Efficiency}

Keywords: car, vehicle, operational efficiency, body, suspension, road evenness, obstacle, shock absorber, technical condition, tire pressure, oscillations, unsprung and sprung masses, simulation, two-mass equivalent structure.

\section{Introduction}

Ride comfort is one of the most important characteristics of the vehicles quality. The vibrations in the vehicle body occur due to the road surface irregularities. Vehicle's suspension system is aimed to support vehicle weight, maintain correct vehicle ride height, keep the tires in contact with trail and prevent damage from impacts with obstacles. Vehicle's suspension is very important when driving on a bumpy road or over obstacles. Suspension protects the car and the passengers from damage when the car goes over a big bump.

\section{Problem Statement}

Changing of the technical condition parameters of the suspension requires continuous improvement of algorithms and methods of diagnostics from the operating staff for providing quality technical operation of vehicles. [11] Maintenance of an original technical condition of a suspension is among the basic requirements of road safety ensuring. The main element which determines the technical condition of the suspension is a shock absorber. The shock absorber of the suspension requires regular diagnostics, which should be performed with the help of specialized stands at the service stations. Specialized stands allow simulating the movement of the vehicle on an uneven road by imitating the movement of the wheel. Such element as shock absorber has the most influence on the serviceability of the suspension, so its condition must be checked often. The durability of the shock absorbers depends primarily on their quality, the road surface condition on which the vehicle is operated and the manner of driving. If faulty shock absorbers are at one side of the vehicle, the motion on uneven road surface will alter the lean of the car's body in the same direction and, when the car will brake, it can result in a skid. Also, the condition of the tire and the air pressure in it have the significant influence on serviceability of the vehicle's suspension. Today, a large number of vehicle owners, especially of vehicles temporarily imported with foreign registration, don't pay enough attention to maintenance of a technical condition of the vehicle, affecting not only the comfort of movement but to ensure safety, what stipulates the choice of research topic.

\section{Review of Modern Information Sources on the Subject of the Paper}

In investigation of the process of interaction of a vehicle with a road surface were engaged such scientists as Raympel J. [7, 8], who was focused on the design of the suspension of the car, Artyushenko A. [12] was researching the smoothness of the car ride, Pavlenko V. M. [13] investigated the methods of diagnosing the suspension and many other scientists: Yevtjukov S.S. [3], Savchuk V.P. [9], Sokolovskyi S.A. [10]. However, none of the authors hasn't devoted attention to the influence of the malfunction of suspension elements on suspension characteristics and, especially, the interaction of malfunctions.

\section{Objectives and Problems of Research}

The purpose of the research was to define the influence of suspension elements, in particular, malfunctions of the shock absorber and air pressure in tires on the operational efficiency of the vehicle. In order to realize the purpose, the task established in the paper is to explore interconnection between displacement of the body and unsprung masses of the vehicle, when the wheel is riding over different types of obstacles at different tire pressures and different speeds of a vehicle with a proper and faulty shock absorber. According to the results of the research, a model of a two-mass scheme of driving over the obstacles for the sprung and unsprung masses in the Subsystem should be constructed and the results of the research should be compared.

\section{Main Material Presentation}

To investigate the impact of a shock absorber malfunction and changes in tire pressure on the car's indications when vehicle is overcoming different types of obstacles at different speeds, methods of 


\section{Roman Kachmar, Andrii Muzychuk, Olena Lanets, Yurii Porokhovskyi}

experimental research have been developed, using the example of the VAZ-210740 car. For measuring and recording indications of the experimental researches it was used analogue-digital converter IRIS USB Oscilloscope (Fig. 1), which, in cooperation with the IRIS Waveware program, allows to get the change in the voltage of the sensor-analyzers of the wheel and car body relative to the road in the real-time mode.

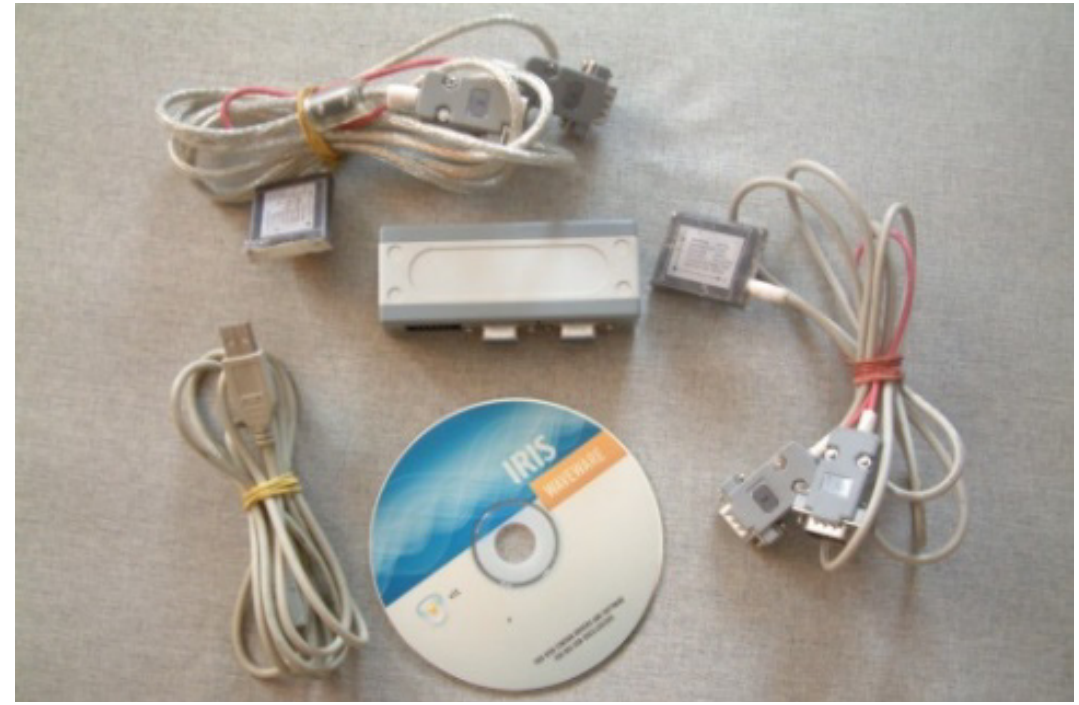

Fig. 1. The IRIS USB Oscilloscope device, which is used for research of the car suspension

For carrying out of experimental researches of the suspension during riding of a car VAZ-210740 over the obstacles, the front right wheel is chosen as an object of research of the unsprung mass. Exactly the right wheel receives the most loads from road unevenness while usual car ride, and the front one, because the front axle is more influential to the lean of the car's body and is responsible for the safety of the car driving.

The IRIS USB Oscilloscope sensors are rigidly fixed to additional structures, one is on an unsprung mass of the vehicle (Fig. 2, position 1), and the other one is on the body of this vehicle (Fig. 2, position 2). These locations are the most convenient for mounting of sensors to the car without interfering its movement over obstacles, and it provides true indications of oscillations in software [8].

To record the dynamic parameters of the car movement during experimental researches of the suspension, it was developed a software-hardware complex, which consists from the next elements: sensoranalyzer, the IRIS USB Oscilloscope analogue-digital converter, the USB cable, the personal computer with the Iris Waveware software for processing and recording the data from installed sensors. Sensoranalyzer perceives linear displacement and converts the received data into the electrical signal [5].

With the aim to determine the impact of operational indicators of the suspension and tires of the car VAZ, it was proposed to change the pressure in the tire in conjunction with the available malfunction of the shock absorber. The malfunction of the shock absorber was imitated by its disassembly, what is allowed by the independent suspension structure. The range of pressure variations in the tire was divided into three values of pressure in the car tire: 1 - the tire is fitted with a pressure of $0.15 \mathrm{MPa} ; 2$ - tire with standardized pressure $0,19 \mathrm{MPa}$ as specified in the recommendations of the car operation; 3 - tire with an increased pressure of $0,25 \mathrm{MPa}$.

Experimental researches were carried out by measuring of the unsprung mass oscillations and the car body oscillations with a proper shock absorber and with faulty shock absorber.

Experimental road researches for determination the dependence of oscillations of the car body and its wheel were carried out at two speeds of the car $(20$ and $30 \mathrm{~km} / \mathrm{h})$ by the methods of various types of moving. These speeds are chosen from the average speed of motion in of city conditions taking in account the previous intensive braking of the car after the detection of obstacles for the motion. Also, this speed is the limit speed which allows relatively safe car driving without shock absorbers when driving on an uneven road due to loss of controllability. 

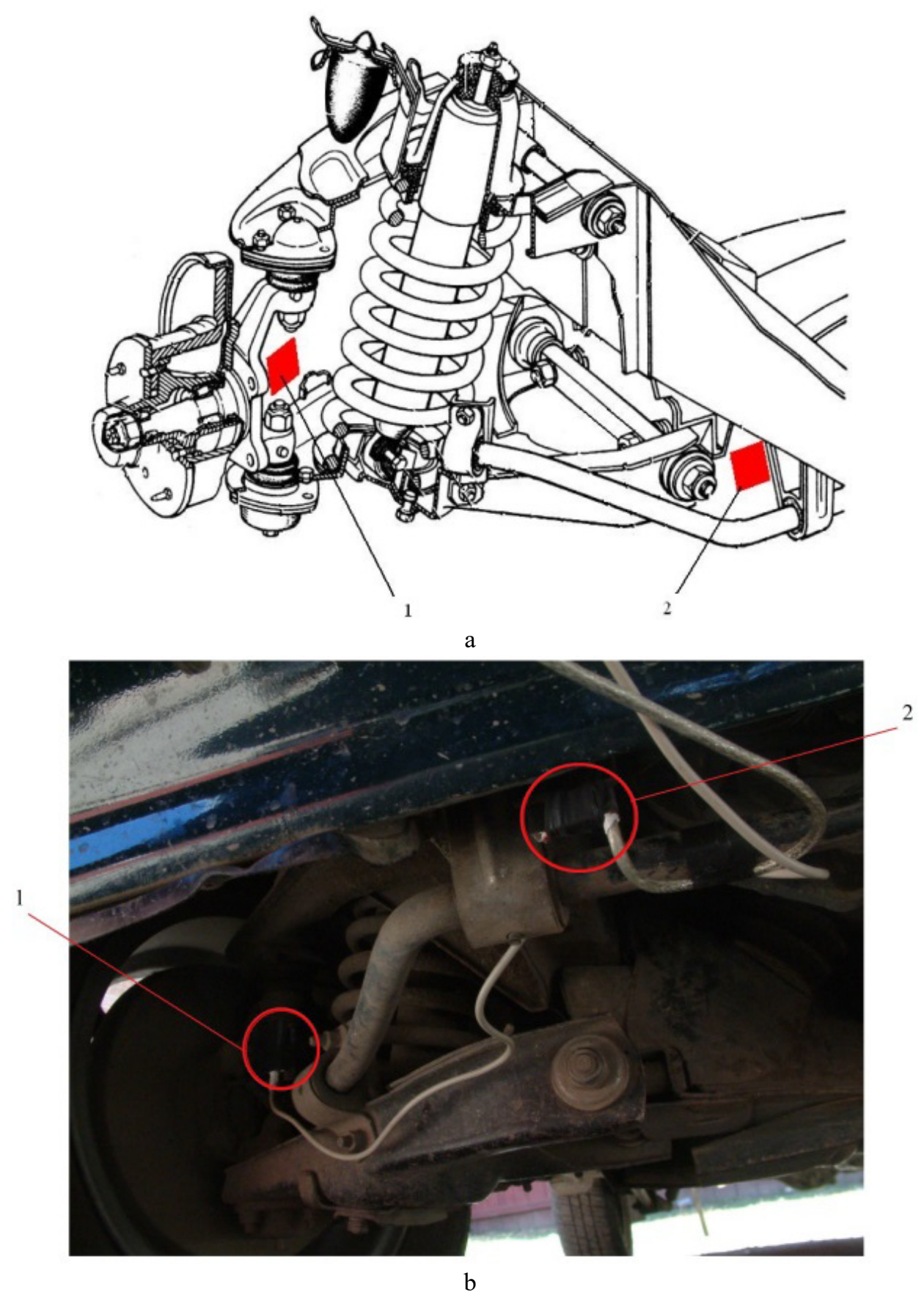

Fig. 2. Schematic location of sensors-analyzers (a) and photo of location on the car (b) during the experimental research: 1 - installation of the sensor on the unsprung mass; 2 - installation of the sensor on the car body

For the experimental research, three types of obstacles were chosen: the first one is a one-time obstacle (Fig. 3), the second one is a double obstacle, and the third one is a long obstacle (Fig. 4).

The first one-time obstacle is a beam with a hollow rectangular cross-section of $40 \times 60 \mathrm{~mm}$. The height of the obstacle was chosen from researches [8], where the author chose an obstacle of $40 \mathrm{~mm}$ height for a soft suspension, because this distance is almost equal to the half the suspension travel both up and down and is equal to the average unevenness of the road.

The second, double obstacle, was represented by two hollow beams with the cross-section of $40 \times$ $60 \mathrm{~mm}$ located at a distance of $1200 \mathrm{~mm}$ between them, with the aim to impose of disturbance attenuation from passing over the first obstacle on disturbance from the second one, and the occurrence of the wave oscillations resonance together with the second obstacle. 


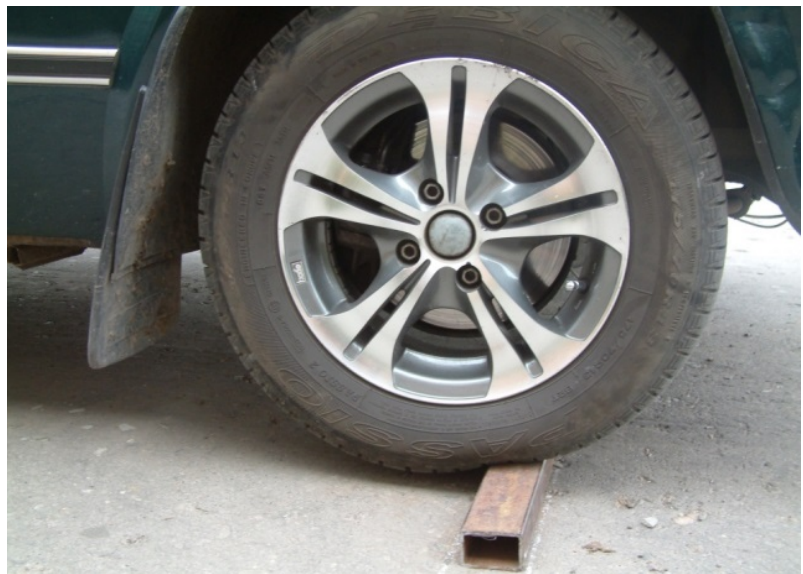

Fig. 3. Photo of the car's tire hits the one-time obstacle

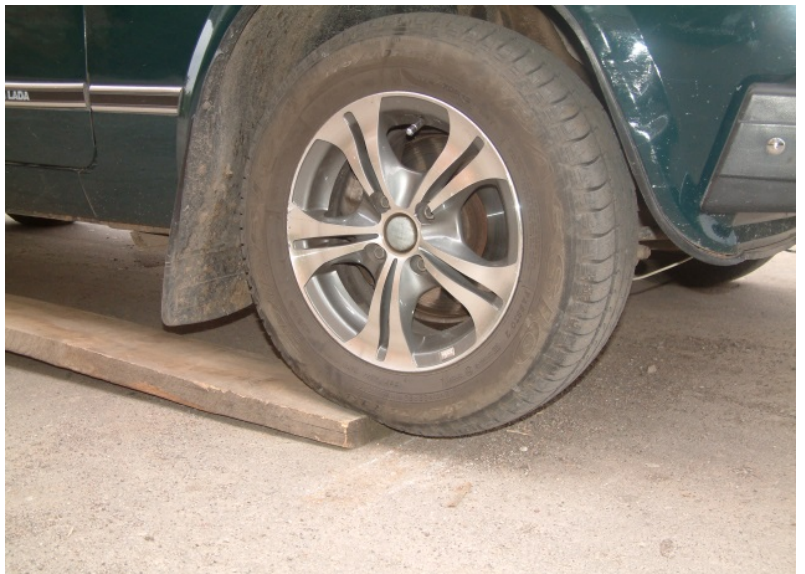

Fig. 4. Photo of the car tire ride off a long obstacle

The long obstacle is a board an $1160 \mathrm{~mm}$ long with a $40 \times 200 \mathrm{~mm}$ cross-section. The length of the long obstacle was also chosen so that disturbance from hitting the obstacle will reach to the damping of oscillations, or that the resonance of the waves could be seen, both from hitting the obstacle, and driving off the obstacle.

According to the result of the speed changes of passing over the obstacle, changes in the tire pressure, changes in the type of obstacles, changes in the suspension condition (normal, faulty), the plan of experiment with the VAZ car was prepared, the change of indicators was carried out at the limit values and in the average point for tire pressures and boundary conditions for shock absorber. For each of three types of obstacles 12 experiments were carried out, with three different pressures in the tire, with two different speeds, and with or without shock absorber, hitting the obstacle was repeated three times.

The change of voltage was obtained on the sensors-analyzers of the unsprung mass and the car body relative to the road surface with different conditions of experimental research.

While driving vehicle VAZ 2107 over one-time obstacle of rectangular cross-section 40x60 at a speed of $20 \mathrm{~km} / \mathrm{h}$ and with tire pressure of $0.15 \mathrm{MPa}$, it can be seen from the graphs (Fig. 5), that with faulty shock absorber the perturbation of the unsprung mass oscillations is larger (Fig. 5, b) than with proper shock absorber (Fig. 5, a). Also, the amplitude of the oscillation perturbation of the sprung mass is more (Fig. 5, b) when the shock absorber is faulty. An increasing of the amplitude of the unsprung mass perturbation when the shock absorber is faulty can be explained by the elasticity of the tire, which in this research has a pressure, which is $0.05 \mathrm{MPa}$ lower than recommended by the car manufacturer.

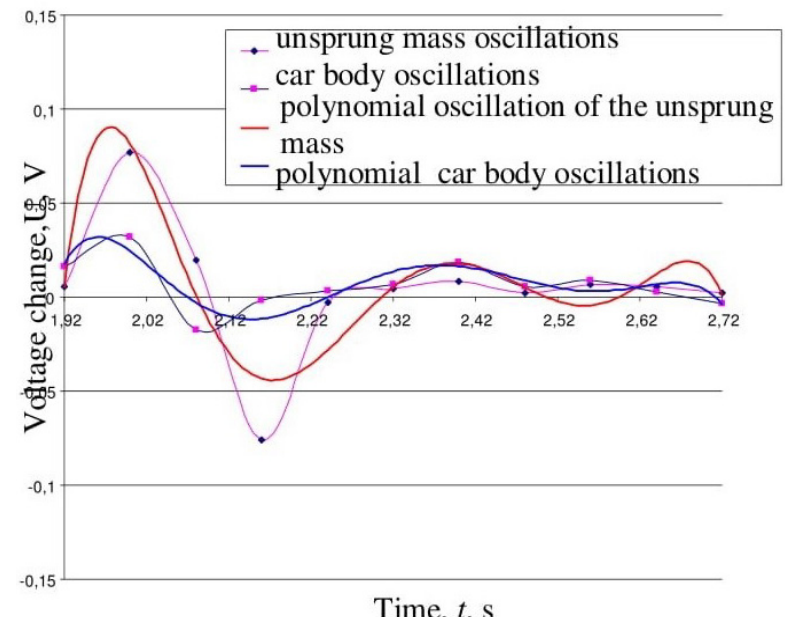

a

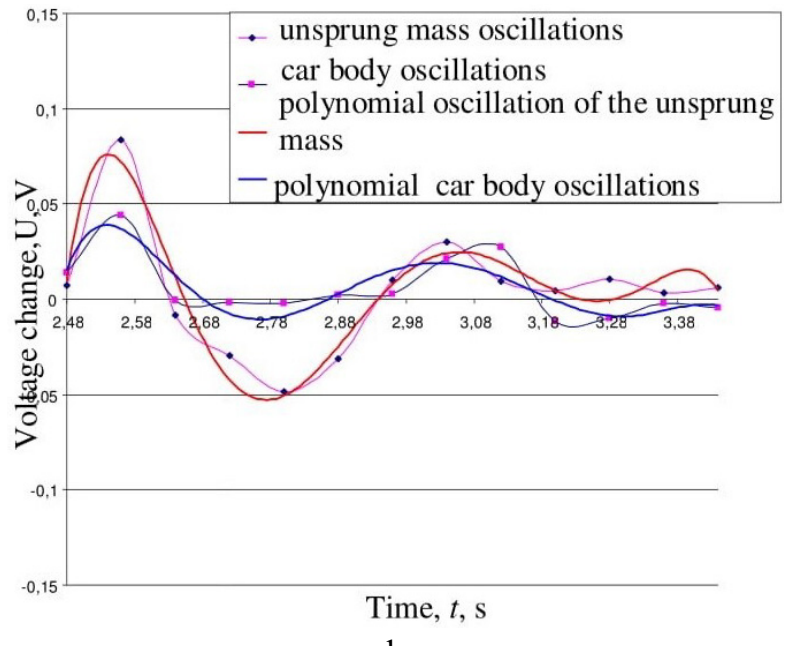

b

Fig. 5. The change of the sensor-analyzers voltage of the wheel and car body relative to the road when riding over a single obstacle (rectangular cross-section $40 \times 60$ ) when a tire pressure of $0,15 \mathrm{MPa}$, at a speed of $20 \mathrm{~km} \mathrm{~h}$; a) with a proper shock absorber; b) with a faulty shock absorber 


\section{The Influence of the Vehicle's Suspension Malfunction on its Operational Efficiency}

With a faulty shock absorber, there is a slight swinging of the car due to the elastic suspension comparatively with a proper shock absorber. The attenuation of the unsprung mass of the car is more visible with a faulty shock absorber because the energy of perturbation is transmitted to the car body.

To transform the change of the sensor-analyzer voltage in to the linear displacement, it is necessary to use the voltage data of the calibrated sensor-analyzers located on the wheel $U_{c l}=66 \mathrm{mV} / \mathrm{g}$ and on the body of the vehicle $U_{c 2}=200 \mathrm{mV} / \mathrm{g}$ (Fig. 2, b), and the amplitude values of the sensors-analyzers of wheel $U_{i 1}$ and of the car body $U_{i 2}$ of [5].

The conversion factor or overload indicator $\xi$ is calculated from the following stipulation:

$$
\begin{gathered}
U_{c j}[B]=g ; \\
U_{i j}[B]=\xi \cdot g,
\end{gathered}
$$

where $\xi$ is overload indicator; $U_{c j}$ is voltage data of calibrated sensor-analyzers; $U_{i j}$ is value of voltage from sensors of analyzers; $g$ is acceleration of free fall $g=9,8 \mathrm{~m} / \mathrm{s}^{2}$.

Therefore, using the condition, the overload indicator is calculated from

$$
\xi_{j}=\frac{U_{c j}}{U_{i j}}
$$

For harmonic fluctuations, the overload $\xi_{j}$ will be determined as

$$
\xi_{j}=\frac{x_{i j} \omega^{2}}{g}
$$

where $X_{i j}$ is the linear values of the amplitude of oscillations converted from the output voltage from the sensors; $\omega$ is the angular frequency of forced oscillations. Therefore, from formula (3) we determine the linear value of the amplitude of the wheel and car body oscillations:

$$
x_{i j}=\frac{\xi_{j} g}{\omega^{2}} .
$$

The angular frequency of forced oscillations is determined by the formula:

$$
\omega=\frac{2 \pi}{T},
$$

where $T$ is the period of attenuation which is taken from the graphs of experimental researches.

The graphs of the oscillations of the wheel and of the car body are calculated by the formula (4) (Figs. 6-8). While driving a car with a proper shock absorber (Fig. 6), with tire pressure $0.15 \mathrm{MPa}$ at a speed of $20 \mathrm{~km} / \mathrm{h}$ over the one-time obstacle, during the experimental researches, it is noticeable that the tire absorbs certain energy from perturbation and the maximum amplitude reaches $29 \mathrm{~mm}$. The oscillations of the body after driving over this obstacle are small - the maximum value of the amplitude is $2.3 \mathrm{~mm}$. The vibration of the car creates noises, under which body oscillations are not much noticeable.
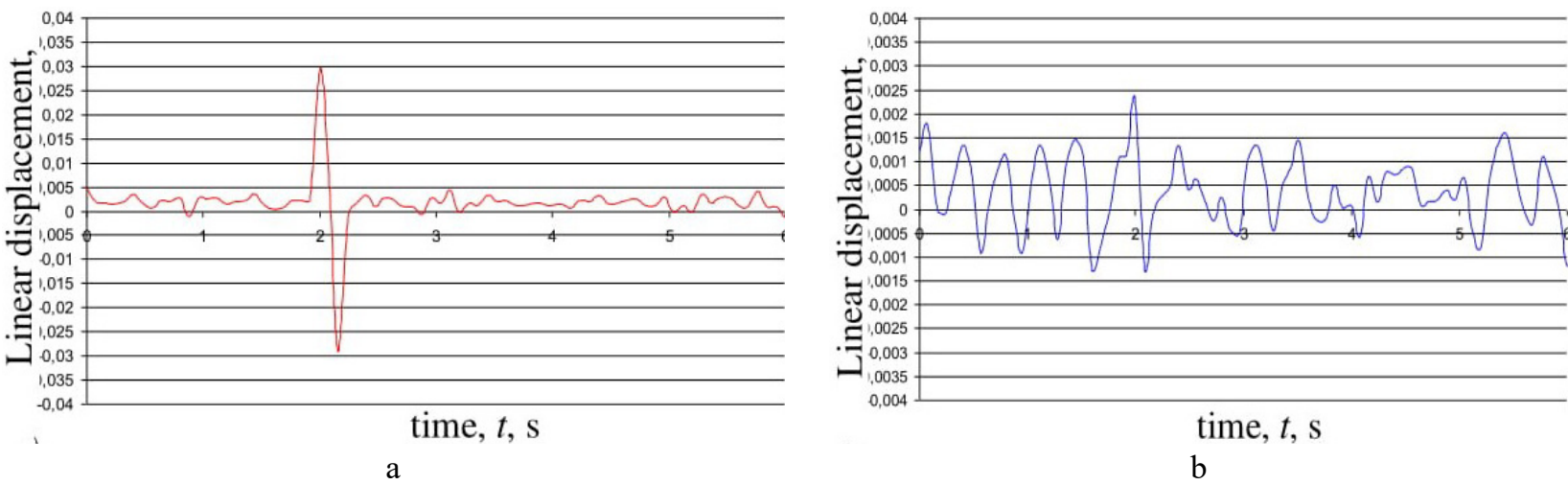

Fig. 6. Fluctuations of the wheel a) and of the car body b) relative to the road when driving over a one-time obstacle (rectangular cross-section $40 \times 60$ ) at a tire pressure of $0,15 \mathrm{MPa}$ at a speed of $20 \mathrm{~km} / \mathrm{h}$ 


\section{Roman Kachmar, Andrii Muzychuk, Olena Lanets, Yurii Porokhovskyi}

According to experimental researches of a passenger car driving over a double obstacle (Fig. 7) with a proper shock absorber with a tire pressure of $0.15 \mathrm{MPa}$ at a speed of $20 \mathrm{~km} / \mathrm{h}$, the wheel's oscillation increases its amplitude to $37 \mathrm{~mm}$ when passing over the second obstacle. This arises in the result of the resonance of waves with oscillations from the first obstacle. The oscillations of the car body are the maximum value of the amplitude of $3.4 \mathrm{~mm}$ at the minimum value of the amplitude of the oscillations of the wheel from the driving over the first obstacle.
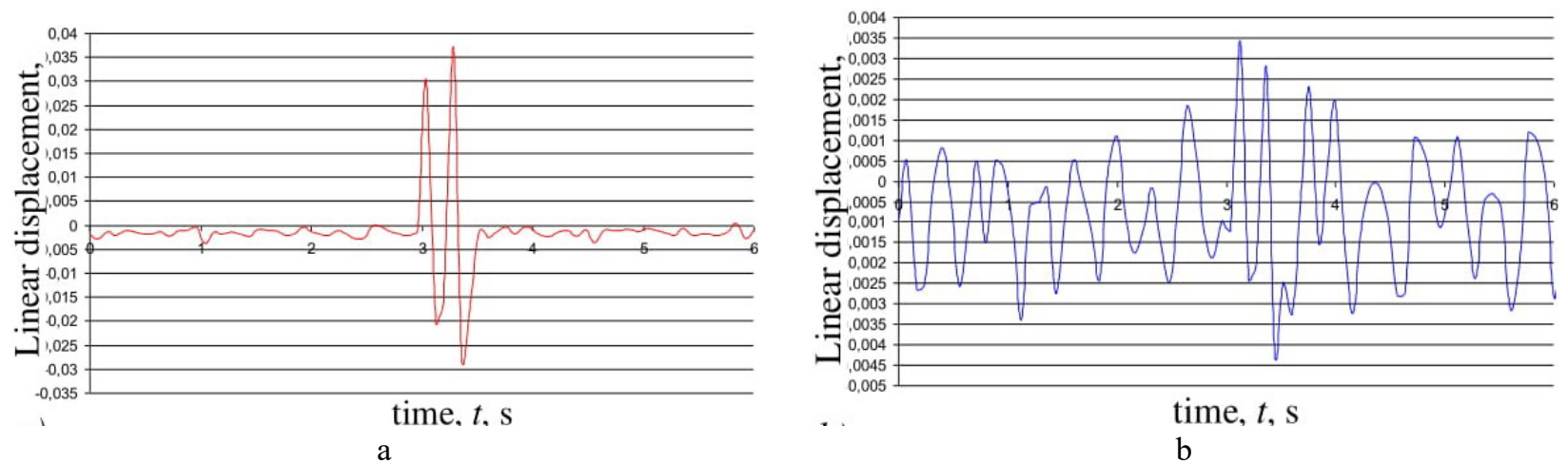

Fig. 7. Fluctuations of the wheel a) and the body b) of the car relative to the road while driving over a double obstacle (rectangular cross-section $40 \times 60$ ) at a tire pressure of $0,15 \mathrm{MPa}$ at a speed of $20 \mathrm{~km} / \mathrm{h}$

The graphs of the experimental researches of the driving over a long obstacle at a speed of $20 \mathrm{~km} / \mathrm{h}$, a tire pressure of $0,15 \mathrm{MPa}$ and with a proper shock absorber are shown at Fig. 8. The maximum amplitude of the oscillation of the wheel reaches $18 \mathrm{~mm}$, visible oscillations while driving off the obstacle, which mirrorly reflects the oscillations of the hitting the obstacle and arises at that moment when fading oscillations from the hitting the obstacle are absorbed. The maximum oscillations of the car body are 20 $\mathrm{mm}$ there, because of the resonance of the waves from the perturbation and the driving off.

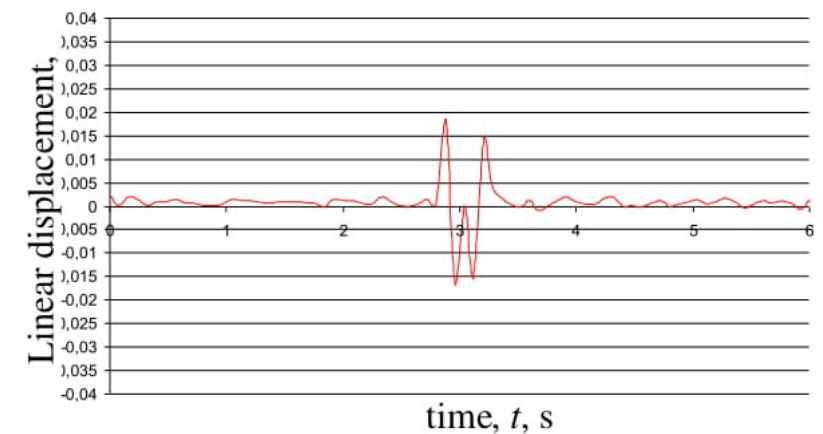

a

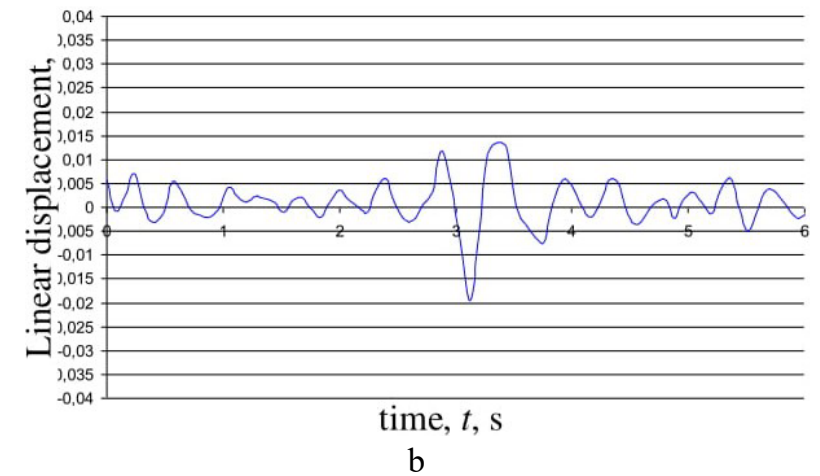

$\mathrm{b}$

Fig. 8. Fluctuations of the wheel a) and body b) of the car relative to the road while driving over a long obstacle (rectangular cross-section $40 \times 1160 \mathrm{~mm}$ ) at a tire pressure of $0,15 \mathrm{MPa}$ at a speed of $20 \mathrm{~km} / \mathrm{h}$

To prove theoretical researches of the car body vertical oscillations level relative to the road surface, the variations of the two-mass scheme equivalent to the car suspension for three types of obstacles (Fig. 9) are considered, and a method for calculating the dynamic dependencies and characteristics of the car suspension are developed using the MATLAB program in the Simulink environment. In the general case, it consists of kinematically linked sprung and unsprung car masses. To the sprung mass of the car includes all its elements, the weight of which is transmitted to the elastic elements of the suspension. Elements on which the weight is not transmitted through the elastic elements of the suspension are called unsprung elements of the car.

Consequently, a sprung mass includes the car body and all the mechanisms that are attached to it, and an unsprung mass includes wheels with axles and the elements of their joints.

Therefore, the oscillation scheme depends on $m_{1}$, which is the sprung mass of the car, and $m_{2}$, which is the unsprung mass of the car, what are linked together by the spring with rigidity $c_{2}$ and a shock absorber 


\section{The Influence of the Vehicle's Suspension Malfunction on its Operational Efficiency}

with damping coefficient $\beta_{2}$. Unsprung mass linked with the road including the tire elasticity $c_{1}$ and the damping coefficient of the tire $\beta_{1}$ [10].

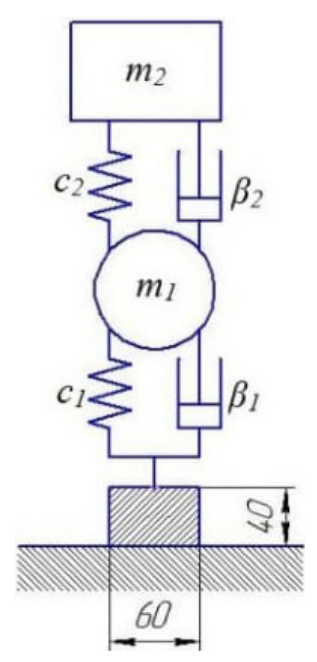

a

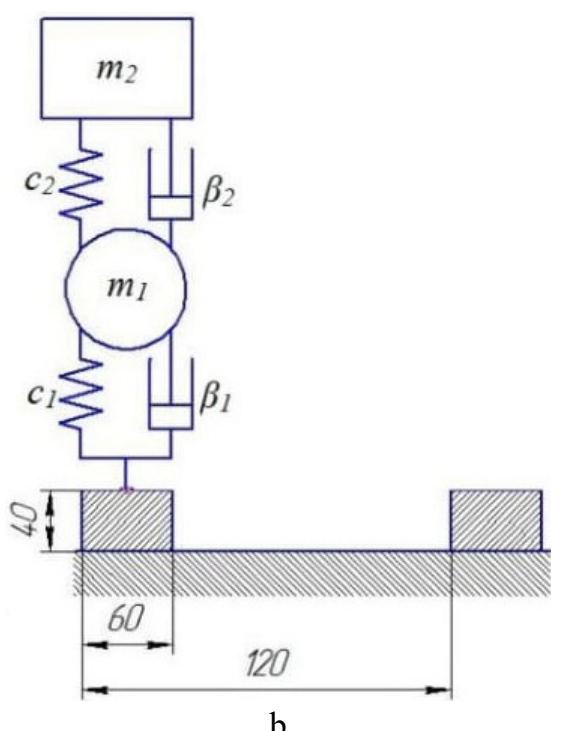

$\mathrm{b}$

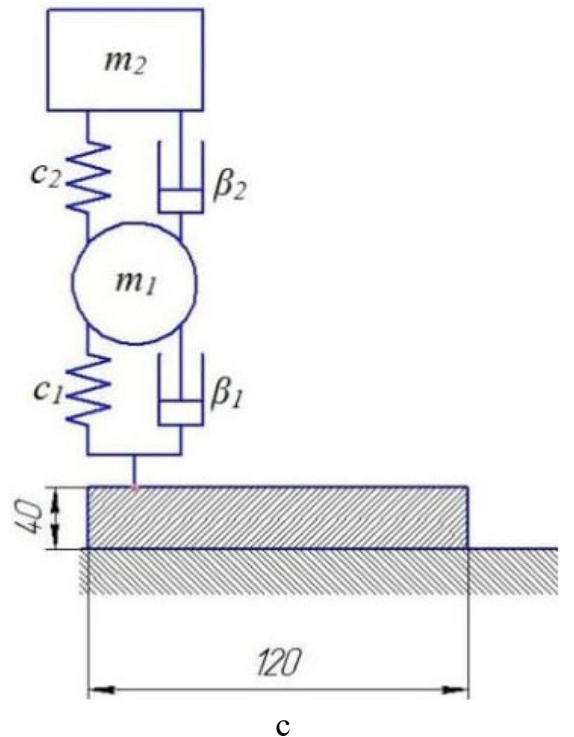

c

Fig. 9. Schematic image of the obstacles for two-mass system: a - a one-time obstacle; $b$ - a double obstacle; $\mathrm{c}$ - a long obstacle

Except the simple obtaining of equations, the analysis of simplified schemes is possible without the use of computing means, which is practically impossible without the application of the scheme. The twomass system (Fig. 9) gives the opportunity to analyze the wheel or car body vibrations in the case of a rigid suspension of the vehicle or in a case of its malfunctions.

The equations of oscillations for the system are composed on the basis of the Lagrange's equation of the second kind. Its general form it is

$$
\frac{d}{d t}\left(\frac{\partial}{\partial \dot{y}}\right)-\frac{\partial T}{\partial y}-\frac{\partial \Pi}{\partial y}-\frac{\partial \Phi}{\partial y}=Q(t)
$$

where $T$ is the kinetic energy of the system; $\Pi$ is the potential energy of the system; $\Phi$ is function of dissipation; $Q(t)$ is a generalized force; $y$ is a generalized coordinate.

The resulting equations are solved in the Simulink graphical environment (integrated with MATLAB). In the developed model the parameters of the real vehicle are set.

The system of equations of motion will have the next form:

$$
\left\{\begin{array}{l}
m_{1} \dot{y}_{1}+c_{1}\left(y_{1}-y_{0}\right)+c_{2}\left(y_{1}-y_{2}\right)+\beta_{1}\left(\dot{y}_{1}-\dot{y}_{0}\right)+\beta_{2}\left(\dot{y}_{1}-\dot{y}_{2}\right)=0 ; \\
m_{2} \ddot{y}_{2}-c_{2}\left(y_{1}-y_{2}\right)-\beta_{2}\left(\dot{y}_{1}-\dot{y}_{2}\right)=0,
\end{array}\right.
$$

To carry up a model in Simulink, it is more convenient to use the following equation:

$$
\left\{\begin{array}{l}
\ddot{y}_{1}=\frac{1}{m_{1}}\left[-c_{1}\left(y_{1}-y_{0}\right)-c_{2}\left(y_{1}-y_{2}\right)-\beta_{1}\left(\dot{y}_{1}-\dot{y}_{0}\right)-\beta_{2}\left(\dot{y}_{1}-\dot{y}_{2}\right)\right] ; \\
\ddot{y}_{2}=\frac{1}{m_{2}}\left[c_{2}\left(y_{1}-y_{2}\right)+\beta_{2}\left(\dot{y}_{1}-\dot{y}_{2}\right)\right],
\end{array}\right.
$$

A model is built in Simulink (Fig.10). Parameters for simulation are the next: unsprung mass $m_{1}=24 \mathrm{~kg}$ [1]; sprung mass, which is distributed on the front axis on one wheel under loading of the vehicle by two passengers $(150 \mathrm{~kg}) m_{2}=315,5 \mathrm{~kg}$ [1]; rigidity of the tire: - with low pressure $c_{11}=125 \mathrm{kN} / \mathrm{m}$; with normalized pressure $c_{12}=135 \mathrm{kN} / \mathrm{m}$; - with excess pressure $c_{13}=155 \mathrm{kN} / \mathrm{m}$ [2]; the damping factor of the tire is the same for three variants, because it is much lesser than the shock absorber damping factor $\beta_{1}=30 \mathrm{Ns} / \mathrm{m}$ [7]; the stiffness of the suspension's spring $c_{2}=35 \mathrm{~N} / \mathrm{m}$ [7]; shock absorber damping factor $\beta_{2}=407 \mathrm{Ns} / \mathrm{m}[3,9]$. 


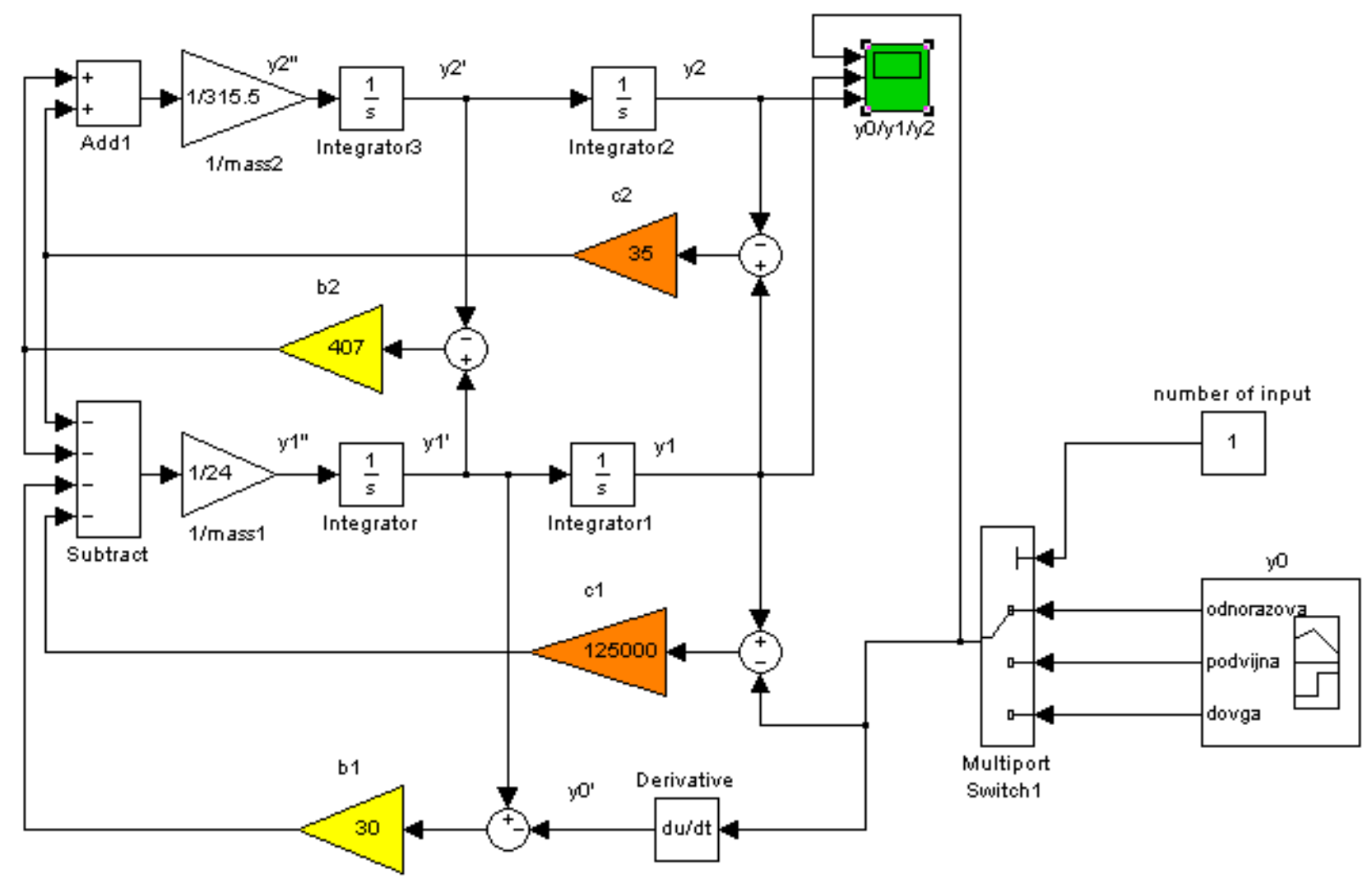

Fig. 10. Two-mass model in Simulink

While developing of the Simulink model of a similar perturbations from the obstacles, it is required to use subsystems (Subsystem) because of the complexity of the equations, their number and type of obstacle, where it is possible to enter the height of perturbation $h$, the initial time $t_{n}$ for which the car passes the distance to the obstacle, the time of passing over the obstacle $t_{1}$, the time of driving the distance between the obstacles $t_{2}$ and the time of driving over the long obstacle $t_{3}$. The types of the obstacles are changed using the Multiport subsystem (Fig. 10).

The speed of the motion is accepted $v=20 \mathrm{~km} / \mathrm{h}$, since the research was carried out with such speed; the initial time of the riding on is taken from the previous researches $t_{n}=2.42 \mathrm{~s}$, and the time of driving over one obstacle $t_{1}$, the time of driving between two obstacles $t_{2}$ and the time of passing over the long obstacle $t_{3}$ will be calculated

$$
t_{i}=\frac{S_{i}}{V_{i 1}}
$$

After substituting into the formula (9) the length of the obstacle $S_{1}=0.06 \mathrm{~m}$, length between the obstacles $S_{2}=1.2 \mathrm{~m}$, length of the long obstacle $S_{3}=1.16 \mathrm{~m}$, it will be obtained $t_{1}=0.0108 \mathrm{~s}, t_{2}=0.2118 \mathrm{~s}$, $t_{3}=0.2158 \mathrm{~s}$.

After starting the program, the graphs of the dependences of unsprung and sprung masses oscillations relative to the road surface were obtained (Fig. 11), which show the oscillations simulated for the car VAZ 2107 in Simulink while driving over the one-time obstacle of the rectangular cross-section of $40 \times 60 \mathrm{~mm}$ with a proper shock absorber at a speed of $20 \mathrm{~km} / \mathrm{h}$ and a tire pressure of $0.15 \mathrm{MPa}$

In Fig. 12 the graphs of the unsprung mass and car body oscillations had simulated in Simulink, while driving over a double obstacle of a rectangular cross-section of $40 \times 60 \mathrm{~mm}$, which are placed at the distance of $1.2 \mathrm{~m}$ one after another, at a speed of $20 \mathrm{~km} / \mathrm{h}$ and a tire pressure of $0.15 \mathrm{MPa}$.

The oscillations of the unsprung and sprung masses relative to the road while passing over one long obstacle $40 \times 1160 \mathrm{~mm}$ with a tire pressure of $0.15 \mathrm{MPa}$ at the constant speed of $20 \mathrm{~km} / \mathrm{h}$ simulated in Simulink are shown in Fig. 13. 


\section{The Influence of the Vehicle's Suspension Malfunction on its Operational Efficiency}

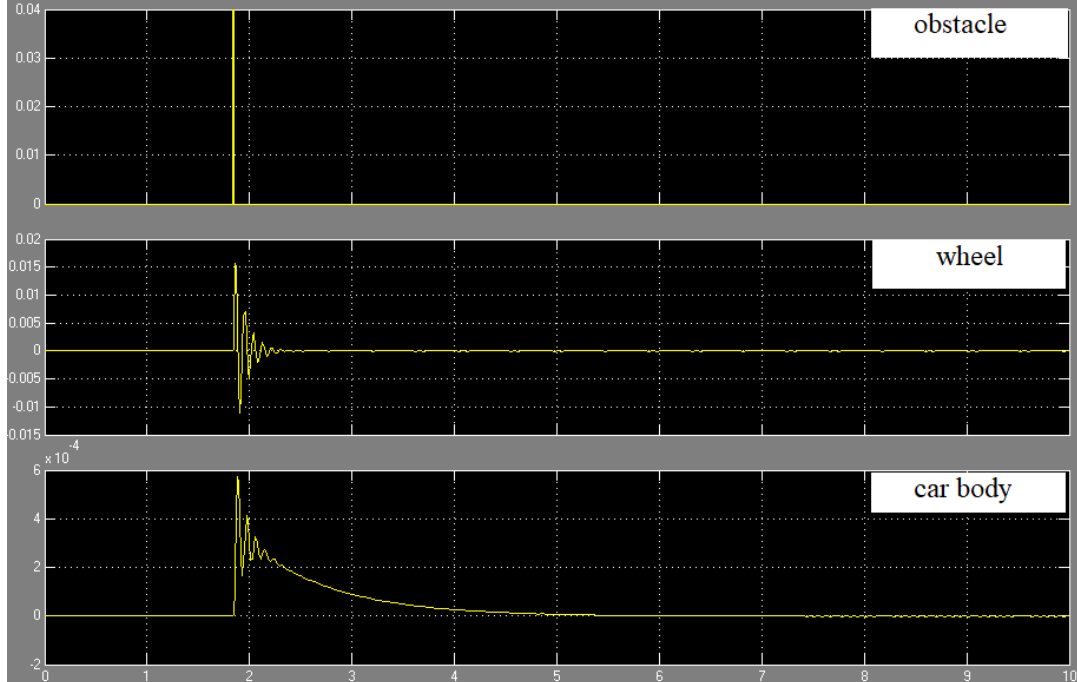

Fig. 11. Oscillations of unsprung and sprung masses in relation to the road with a tire pressure of $0.15 \mathrm{MPa}$ and a speed of $20 \mathrm{~km} / \mathrm{h}$ while passing over one-time obstacle with a proper shock absorber

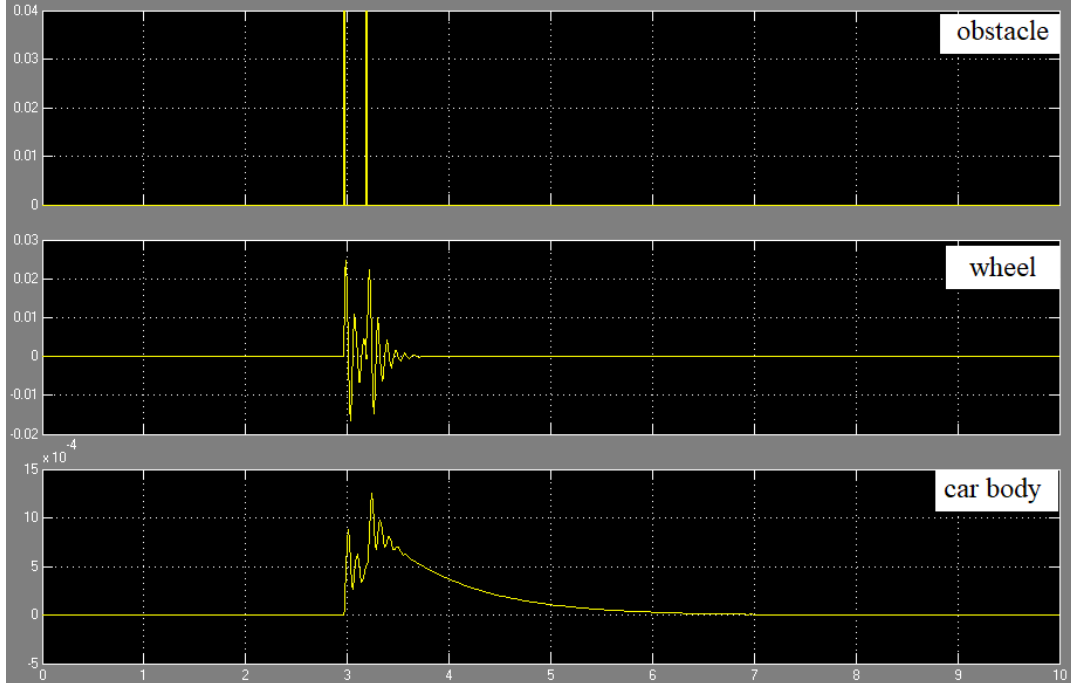

Fig. 12. Oscillations of unsprung and sprung masses in relation to the road with a tire pressure of $0.15 \mathrm{MPa}$ and a speed of $20 \mathrm{~km} / \mathrm{h}$ while passing over the double obstacle with a proper shock absorber

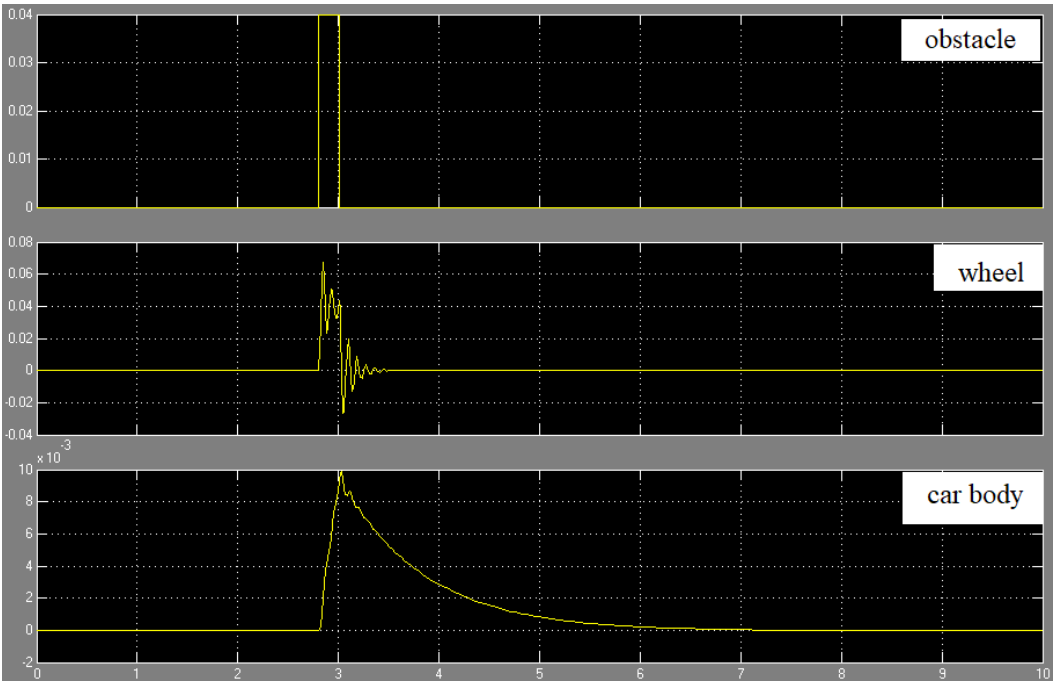

Fig. 13. Oscillations of unsprung and sprung masses in relation to the road with a tire pressure of $0.15 \mathrm{MPa}$ and a speed of $20 \mathrm{~km} / \mathrm{h}$ while passing over a long obstacle with a proper shock absorber 


\section{Roman Kachmar, Andrii Muzychuk, Olena Lanets, Yurii Porokhovskyi}

\section{Conclusions}

As the experimental researches demonstrated, the changes of the sensor-analyzer's voltage for the unsprung mass and body of the car while driving over the different types of obstacles, the tire pressure affects the operational performance and durability of the tire.

According to the results of research, both experimental and theoretical, the tire pressure determines the characteristics of perturbing and fading oscillations, at a speed of $20 \mathrm{~km} / \mathrm{h}$ in a technically efficient vehicle with a tire pressure of $0.15 \mathrm{MPa}$, while driving over a one-time obstacle the maximum amplitude of the wheel's oscillations is $30 \mathrm{~mm}$, and car body is $2.3 \mathrm{~mm}$. When riding over a double obstacle, the maximum amplitude of the oscillations of the wheel is $37 \mathrm{~mm}$, and of the car body is $3.4 \mathrm{~mm}$. The maximum amplitude of the oscillations of the wheel is $18 \mathrm{~mm}$ and the car body oscillations are $14 \mathrm{~mm}$ while riding over a long obstacle.

The technical condition of the shock absorber on the VAZ car, according to the results of experimental research, significantly changes the nature of fading of the suspension oscillations. The serviceability of the shock absorber determines the maximum displacement of the car body and wheel, in particular, with a proper shock absorber with a nominal tire pressure of $0.19 \mathrm{MPa}$, while driving over a one-time obstacle, the maximum amplitude of wheel oscillations is $41 \mathrm{~mm}$ and the car body oscillations amplitude is $2.9 \mathrm{~mm}$ at a speed of $20 \mathrm{~km} / \mathrm{h}$ for one-time obstacle.

Also, the type of obstacle determines the maximum amplitude of the wheel and car body vibrations. Two obstacles, where one follows another obstacle, are the most dangerous for the vehicle's suspension, in this occasion the oscillations of perturbation from the second obstacle are of higher amplitude value than from the first one, due to the occurrence of resonance with fading oscillations from the first obstacle.

As experimental studies have shown, part of the energy of perturbation generated by the vibration stand at the diagnosis of the shock absorber and the suspension, in general, will be lost, or vice versa, will increase due to the pressure in the tire. With a reduced tire pressure of $0.05 \mathrm{MPa}$, when riding over a onetime obstacle at a speed of $20 \mathrm{~km} / \mathrm{h}$ with a proper shock absorber, the amplitude of the wheel and car body oscillations was decreased, the same as with a faulty shock absorber, but the oscillations of the car body with a faulty shock absorber were double times increased, if to compare with the nominal tire pressure.

Oscillations of the wheel of the car, while riding over a one-time obstacle with increased pressure in the tire to $0.25 \mathrm{MPa}$ with a proper shock absorber, is reduced almost twice, but the period of fading the car body oscillations increases with decreasing of the amplitude.

With a faulty shock absorber, with increased pressure in the tire, car body oscillations are increased, and the wheel vibrations are reduced if to compare them with oscillations under nominal pressure and faulty shock absorber.

Consequently, the tire pressure has an important part, both in diagnostics and in the operation of the car. With a difference in pressure at $0,03 \mathrm{MPa}$, an unpredictable situation can occur which can cause to sad consequences, on the even road or in a difficult road situation either in difficult weather conditions. Also, if the tire pressure is less than nominal, then the lean of the tire itself increases while cornering and the yaw of the car is possible.

Also, the malfunction of the shock absorber, first of all, causes a danger and discomfort when operating the car. Characteristic of a normal shock absorber is designed so that the wheel only could travel once up and turns downwards, and after that, $80 \%$ of the shock energy is damped by the shock absorber and is converted into heat that dissipates in the air. Without a shock absorber, the spring tends to turn the wheel into a grip with a road surface, but when it hits - it bounces back. The car hits new obstacles and bumps, and if it were without shock absorbers, then at a speed of more than $30 \mathrm{~km} / \mathrm{h}$ it would be practically impossible to control it. The results of the research can be used to optimize the methods of diagnostics of the suspension of the vehicle and to further research in order to improve the comfort of passengers and the reliability of the suspension elements. 


\section{The Influence of the Vehicle's Suspension Malfunction on its Operational Efficiency}

\section{References}

[1] K. B. Piatkov, A. P. Ihnatov, and S. N. Kosarev Avtomobili semeistva VAZ-2107. Rukovodstvo po tekhnicheskomu obsluzhyvaniiu i remontu. S rekomendatsyiamy zhurnala "Za rulom" [Cars of the VAZ-2107 family. Manual for maintenance and repair. With the recommendations of the magazine "Za rulom"]. Moscow, Russia: ZAO «KZhY» Publ., 2004. [in Russian].

[2] V. A. Damzen, M. A. Trefylov, "Metodika izmereniia staticheskoi zhestkosti avtomobilnykh shyn" ["Method of measuring the static stiffness of automobile tires"], in Proc. 4th Int. Conf. "Dinamika nauchnykh issledovanii - 2008" ["Dynamics of research - 2008"], Sofia, Bulgaria, 2008, pp. 68-70. [in Russian].

[3] S. S. Evtiukov, "Soprotivlenie amortizatora szhatiiu, kak faktor vlijanyia na energeticheskie zatraty avtomobilia pri preodolenii porogovoho prepiatstviia" ["Resistance of shock absorber to compression as a factor in influencing the energy costs of the car in overcoming the threshold obstacles"], Sovremennye problemy nauki $i$ obrazovaniia [Modern problems of science and education], no. 3, pp. 65-71, 2014. [in Russian].

[4] R. Ya. Kachmar, A. V. Muzychuk, "Vplyv nespravnosti elementiv pidvisky lehkovoho avtomobilia na yoho ekspluatatsiinu efektyvnist" ["Influences of injuries of the passenger car suspension elements on its exploitation efficiency"], in Proc. 5th Int. Conf. "Teoriia ta praktyka ratsionalnoho proektuvannia, vyhotovlennia i ekspluatatsii mashynobudivnykh konstruktsii" ["Theory and practice of a rational design, manufacture and operation of engineering constructions"], Lviv, Ukraine, 2016, pp. 86-88. [in Ukrainian].

[5] O. S. Lanets, V. M. Hurskyi, O. V. Lanets, and Ya. V. Shpak, "Obhruntuvannia konstruktsii ta modeliuvannia roboty rezonansnoho dvomasovoho vibrostola z inertsiinym pryvodom" ["Justification of the design and simulation of the operation of a resonant two-mass vibration table with an inertia drive"], Visnyk Natsionalnoho universytetu "Lvivska politekhnika" [Bulletin of Lviv Polytechnic National University], no. 788, pp. 28-36, 2014. [in Ukrainian].

[6] Y. Raimpel, V. P. Agapova, Shassi avtomobilia [Car chassis]. Moscow, Russia: Mashinostroenie Publ., 1983. [in Russian].

[7] Y. Raimpel, V. P. Agapova, Shassi avtomobilia: Amortizatory, shyny i kolesa [Car chassis: Shock absorbers, tires and wheels]. Moscow, Russia: Mashinostroenie Publ., 1986. [in Russian].

[8] Y. Raishel, Shassi avtomobilia: elementy podveski [Car chassis: suspension elements]. Moscow, Russia: Mashinostroenie Publ., 1987. [in Russian].

[9] V. P. Savchuk, "Modelirovanie dvizhenija elementov podveski MacPherson na primere avtomobilei semeistva VAZ 2110" ["Modeling the movement of MacPherson suspension elements on the example of cars of the VAZ 2110 family"], Novi rishennia $v$ suchasnykh tekhnolohiiakh [New solutions in modern technologies], vol. 70, pp. 27-34, 2013. [in Ukrainian].

[10] S. A. Sokolovskyi, "Avtomatyzovanyi rozrakhunok kharakterystyk pidvisky avtomobilia u seredovyshchi modeliuvannia SIMULINK" ["Automated calculation of suspension characteristics of the car in simulation environment SIMULINK"], Zbirnyk naukovykh prats Akademii vnutrishnikh viisk MVS Ukrainy [Collection of scientific works of the Academy of Internal Army of the Ministry of Internal Affairs of Ukraine], vol. 1, pp. 17-23, 2014. [in Ukrainian].

[11] Ye. Yu. Fornalchyk, R. Ya. Kachmar, I. V. Terletskyi, "Ekspluatatsiina nadiinist konstruktsii pidvisok lehkovykh avtotransportnykh zasobiv" ["Operational reliability of constructions of suspensions of motor vehicles"], Mashynoznavstvo [Mechanical Engineering], vol. 4, pp. 42-44, 2006. [in Ukrainian].

[12] A. D. Artiushenko, O. H. Suiarkov, "Doslidzhennia vplyvu kharakterystyk pidvisky avtomobilia maloho klasu na plavnist khodu ta yii modernizatsiia" ["Investigation of the influence of characteristics of the suspension of a small class car on the smooth running and its modernization"], Transportne mashynobuduvannia [Transport engineering], vol. 31 (1004), pp. 21-27, 2013. [in Ukrainian].

[13] V. M. Pavlenko, "Stan rozvytku metodiv diahnostuvannia pidvisky avtomobilia" ["Condition of development of methods of diagnostics of the car suspension"], Avtomobile- ta traktrorobuduvannia [Automobile and Tractor Engineering], vol. 64 (970), pp. 63-69, 2012. [in Ukrainian]. 